\title{
Studying Leadership in the Context of Existential Personality Psychology
}

\author{
Alexey V. Morov ${ }^{1,2} \&$ Natalia S. Morova ${ }^{2}$ \\ ${ }^{1}$ East-European Institute, Ighevsk, Russia \\ ${ }^{2}$ Mari State University, Yoshkar-Ola, Russia \\ Correspondence: Natalia S. Morova, Mari State University, Lenina Sq., 1, Yoshkar-Ola, Republic of Mari El, \\ 424000, Russia.
}

\author{
Received: February 21, 2015 Accepted: March 15, $2015 \quad$ Online Published: April 29, 2015 \\ doi:10.5539/res.v7n8p1 URL: http://dx.doi.org/10.5539/res.v7n8p1
}

\begin{abstract}
The author suggests two new principles of addressing the phenomenon of leadership: 1) leadership is an integral trait of personality and represents a person's willingness and ability to influence the environment with his values and ideas. Existential reflection is the necessary basis of leadership. 2) Leadership is a phenomenon of "psychic reality" and may differ from one culture to another. The article describes a series of experiments that examine the personality qualities most frequently associated with leadership in the Russian mass consciousness.
\end{abstract}

Keywords: psychic reality, psychology of personality, existential psychology, existential reflection, proactive psychic activity, leadership, personality traits, repertoire grids technique

\section{Introduction}

Psychology of leadership is one of the popular research topics in contemporary social psychology. It can be explained by the fact that there are now more and more evidence of the influence that acts of leadership can exert on various social processes, ranging from family matters and classroom behavior to running corporations and even nations. In our media-governed world successful leaders quickly become universal role models, with millions aspiring to emulate their life styles and philosophies. Leadership training courses are suggested by all business schools, and books about leadership and its secrets top the charts of best-sellers. However, there is still no recognized system or school that could reliably "produce" leaders. We do not even have an understanding of the notion of leadership that would be shared by majority of researchers and coaches. This contradiction between growing interest to the phenomenon of leadership and the abundance of available information — and distinct lack of serious results in leadership training worldwide, as well as inconsistency of scientific studies of this phenomenon, makes our research important for understanding what leadership truly is and how it can be recognized and developed - provided such development is possible at all.

We suggest two main principles of addressing the phenomenon of leadership that would help overcome both the terminological chaos caused by often contradictory understandings of leadership, and the rift between theoretical studies of the phenomenon and their later practical application. First, we draw a bold line between "leadership" and "administration" and define leadership as an integral trait of personality which is expressed through the person's ability to exert purposeful and targeted influence on other people and socio-psychological processes by means of creating values and organizing activities corresponding to these values. According to this understanding, running a successful corporation does not necessarily make you a leader; in fact, no amount of prestige or profit can make a leader. Leadership is all about inner values and the person's ability to express these values, to find and organize followers - which makes leadership more a personality phenomenon than a function of in-group interaction. Leadership starts with the person creating a system of values that can make people act that can serve as the meaning of their lives. That certainly makes leadership an existential phenomenon, the process of creating, expressing and fulfilling of not only values, but life meanings (as in Viktor Frankl's "Man's Search for Meaning").

Second, we believe that trying to discover any sort of truly universal and objective formula of leadership is counter-productive. Leadership, as any other psychological phenomena, is subjective and can be interpreted and responded to differently by various people and in various circumstances or cultures. That is why leadership 
styles and models that were reasonably successful and effective in USA or Western Europe do not produce similar results when applied in Russia or Oriental countries - they are unable to overcome the differences in cultural codes. So, we suggest studying leadership as a phenomenon of "psychic reality" and paying greater attention to qualities attributed to leaders and leadership by constructs of mass consciousness in a given culture of region.

The main goal of this article is to present our understanding of leadership as a trait of personality and its existential nature, as well as to present the results of our studies of qualities attributed to leaders in various environments within the Russian culture.

\section{Methods}

In our research we used interdisciplinary (sociology, education, psychology) approach combining qualitative and quantitative methods, including the following:

- Comparative analysis of existing works on psychology of personality, psychology of leadership, and existential psychology;

- Theoretical synthesis;

- Studying the personality qualities attributed to leaders, with the help of the repertoire grids technique;

- Lexico-semantic analysis;

- Studying the temperament traits attributed to leaders, with the help of the original questionnaire.

Such research design allows us to achieve deeper understanding of the phenomenon of leadership and of the practical means of expressing existential values created by the leader and establishing effective cooperation between the leaders and the followers.

\section{Results and Discussion}

Defining leadership as an integral trait of personality which is expressed through the person's ability to exert purposeful and targeted influence on other people and socio-psychological processes by means of creating values and organizing activities corresponding to these values, we claim that leadership has existential basis and demonstrates relative but significant independence from the ever-changing realities of socio-psychological environment. The essence of leadership is not in the successful adaptation to this environment, but in the proactive, advance influence, transformation of the environment according to the meanings and values of the leader. Obviously, if a person has no understanding of the meaning of his or her existence, if a person does not express ideas that share this understanding with potential followers - this person cannot become a leader, regardless of organizational, financial or other resources he or she might possess. A leader must be a champion of a certain system of values, he must project this system outwards and start activities that attract followers and make them accept and promote the same values.

This understanding of leadership "upgrades" leadership development from simple mastering of administration and communication skills to the next level of personality development and takes us into the area of adult psychology. Development of personality of an adult is not so extensively studied as the development of personality of a child or a teenager. Exiting works on the development of personality of an adult claim that "crises of adults are not connected with activities or social roles change. They are psychological crises where a person finds himself in a conflict between the demands of his social environment and his own values and aspirations" (Frankl, 1996). We believe that such conflicts of values are the most productive environment for natural development of leadership as an integral trait of personality. When developed, this personality trait will determine the person's reaction to the situation of conflict and the nature of the person's interaction with the society as a whole.

A person cannot have coherent understanding of the meaning of his life without existential reflection that we define as the "person's desire and ability to formulate the meaning of his existence and select motives that help him fulfil this meaning" (Morov, 2014). It is this existential reflection that helps a person establish proactive position in life, following his or her own individual life course and being a true subject in all interactions with the environment rather than just adapting to its changes.

A person's ability to resist external influence and preserve his own life style has been extensively studied in psychology of personality, specifically within the theory of subjectness. Studies of subjectness have had a very significant impact upon the studies of personality in Russia. We would like to give special mention to the representatives of the so called "acmeological" approach in subjectness studies who claimed that subjectness was a special, superior level of personality development and defined subjectness as "personality's ability to search 
and understand personal meaning, formulate individual life goals and not those imposed by the social environment" (Sergienko, 2013).

Our understanding of existential reflection has certain similarities to the acmeological understanding of subjectness. But the key difference is that we claim that subjectness, while certainly am indicator of high personality development, is not the final level of this development. Leadership is the higher level. According to our definition, leadership includes not only resistance to external influence but also a person's ability to exert his or her own advance influence, directed not inwards, but outwards, to the followers.

We can see many examples of people who demonstrate remarkable subjectness but no leadership. For example, a factory worker who resists the inclination to start smoking despite smoking being the behavioral norm in his social environment because he keeps his belief that smoking is bad, certainly shows his subjectness. But he does not demonstrate any leadership because he does not influence the social situation and project his values outwards. We can metaphorically define subjectness as a "psychological shield", a person's ability to defend himself against unwanted external influence and be himself in any situation. Leadership, on the other hand, is a "psychological sword", the means to change the surrounding reality, to transform it according to the leader's beliefs and values (Morov, 2014).

This understanding of leadership requires a different approach to its development - not only as traditional education, but, more importantly, through the development of personality. The new leadership paradigm can become the methodological basis of the new generation of approaches in leadership training through subjectness and then active transformation of social environment.

Moreover, suggested development of the theory of subjectness represents an evolution of existing views on personality development. Contemporary works in the sphere of psychology of personality demands for new personology ideas that would help overcome current personality theory weaknesses, mostly caused by certain incorrect assumptions regarding the problem of determinism in psychology of personality. (Leontiev, 2011) directly claims that contemporary science "overestimates the degree of influence of the environment, heredity, and other factors on our activity because of the lack of knowledge and understanding how we can change anything in ourselves and our lives". We believe that change of personality paradigm-from reactive to proactive, from adaptation to leadership - is one of the ways to overcome contemporary crisis in psychology of personality and start studying the psychological mechanisms of proactive and conscious change that a person can produce in the world.

The idea of proactive personality is not new in psychology. Alfred Adler was the first to state that "simple causality is not enough for a living organism in order to overcome the chaos of the future and lack of plans that we will certainly become victims of. Any our act would be as simple as palpation, no economy of spiritual life would be possible. Without integrity and personal needs we would be as simple as amoebas. Only the non-living can be governed by obvious causality" (Adler, 1995). Viktor Frankl also claimed that intentionality was the necessary basis of human activity and spoke of intentionality as the main difference between human motivation and animal instinct (Frankl, 1996).

As follows from the about quotes, even the representatives of so radically opposed psychological schools as psychoanalysis and existential psychology, still found common ground in the belief that human psychological life is determined by his ability to proactively find meaning and focus and interact with his surroundings being relatively independent from them.

We would like to stress our conviction that determining and formulating one's meaning of life is a product of the person's conscious activity and can be done in any moment of life. A man is free to not only search for meaning, but to construct it. This process of creating the meaning - whether through search or construction -is what we call existential reflection. Making the decision about the meaning of one's existence determines the hierarchy of motives, the means of achieving personal goals, the very nature of interaction with the environment and other people. Existential reflection accompanies the person through the whole life, optimizes his social behavior, and protects him against external influence.

Existential reflection gives essence to the notions of honor, duty, success, right and wrong-thus forming the system of personal values. It does not, however, guarantee that the person will be able to share his values with others and to make them accept these values and follow his lead. Going from subjectness to leadership demands developing additional personality traits that would help interact with followers. Determining the set of these necessary traits is important to understand leadership as really integral, involving not only the intrapsychic existential component, but also the image of leadership in mass consciousness which requires certain behavioral patterns from a would-be leader. While leadership is not possible without existential reflection and personal 
hierarchy of values, ideas and motives, it is equally impossible if a person does not correspond to the "archetype of leader" accepted in the given culture and cannot use this image of leadership to gain additional trust and support from his followers.

When studying psychic reality and its elements, it is very important to make a correct choice of methodological basis for research and tools of psychological diagnostics. We have selected George Kelly's repertory grid technique (RGT). The main peculiarity of Kelly's methodology is its perception of every man as a scientist who makes hypotheses about the world, and then proves or falsifies these hypotheses. A person tries to understand, interpret, predict and control the world of his feelings in order to interact with it more effectively. What is particularly important for us about Kelly's personal construct psychology is its principle that people do not only passively react to the environment, but actively create their opinion of the environment through mental models, or "constructs". People develop constructs as internal ideas of reality in order to understand the world around them (Fransella \& Bannister, 1987). We believe that Kelly's understanding of people perceiving the world through the system of personal constructs is quite close to our thesis of the role of psychic reality in individual reflection of the events of surrounding reality. Thus we can accept the paradigm of cognitive psychology as the methodological basis of our research, and the repertory grid technique as its main experimental method.

The repertory grid is a technique which uses subjective scaling and factor analysis to determine the nature of a person's decision-making and world-views. It is a very flexible diagnostic method that can be easily fine-tuned to reconstruct almost any area of a person's experience and to determine constructs of various complexity and importance (Fransella \& Bannister, 1987)

We organized an experiment to study people's personal constructs associated with leadership and the quality of leader reflected in mass consciousness. The experiment involved 90 interviewees belonging to different social groups: 30 were teachers of pre-school educational institutions, 30 - teachers of secondary school, and the other 30 were managers of an oil company from the Republic of Udmurtia, Russia. Such selection of interviewees was intentional: the teachers are professionals who actively translate social experience to new generations, while managers are those who are charged with authority and targeted by social expectations connected to the notion of "leadership".

The interviewees had to fill three various forms. In the first form they had to write the names of 12 people who they believed to be leaders. Those people could be real or fictional, belong to any historical era, or even be characters from literature or cinematography. The second form contained 12 triads where the names from Form 1 were randomly put together in groups of three. So each leader was mentioned three times in random combination with other leaders. In each triad, the interviewees were asked to determine the psychological quality that united two of the three leaders, and the opposite quality that separated the third leader from the first two. This approach helped us get 12 pairs of opposing constructs from each of the interviewees. Form 3 suggested to assess each of the 12 leaders from Form 1 in each of the construct pairs from Form 2. The interviewees gave out marks ranging from 1 to 7 where 1 meant the maximum representation of one quality, and 7-the maximum representation of its opposite. The experiment generated hundreds of constructs and helped us not only determine the most frequent constructs but also to understand their "weight", relative importance as parts of "archetype of leader" existing in the Russian mass consciousness.

Since the objective of our research was to study not the individual opinion of leadership but the general image of leadership shared by significant parts of interviewees, we will mention here only the constructs that were used by more than a half of the interviewees.

Table 1. The most frequent constructs associated with the notion of "leadership"

\begin{tabular}{lllllll}
\hline Construct & \multicolumn{2}{l}{ Pre-school workers } & \multicolumn{2}{l}{ School teachers } & \multicolumn{2}{l}{ Managers } \\
\cline { 2 - 6 } & Frequency & Weight & Frequency & Weight & Frequency & Weight \\
\hline Ambition & $53 \%$ & 2.5 & $63 \%$ & 2.3 & $27 \%$ & 2.1 \\
Determination & $63 \%$ & 2.0 & $60 \%$ & 2.5 & $50 \%$ & 2.2 \\
Impulsiveness & $50 \%$ & 2.0 & $57 \%$ & 2.0 & $37 \%$ & 2.0 \\
Hot temper & $60 \%$ & 2.2 & $53 \%$ & 2.3 & $57 \%$ & 2.1 \\
\hline
\end{tabular}


Both groups of workers of education provided similar most frequent constructs: ambition, determination, impulsiveness, and hot temper. These qualities were not only the most frequent but also the most important, with maximum "weight" marks from Form 3 ( 2 and more out of possible 3). Despite slight differences between the results in the first two experimental groups, we can say about significant similarities in perception of leadership among the representatives of educational institutions, both of pre-school and school level. In both groups, ambition and determination were named as the most important qualities of leaders. If an opposite quality, for example cautiousness, is pronounced, such person cannot be perceived as a leader. It should be noted that such qualities as ethics or morals were mentioned very seldom, which does not allow us to consider these qualities as attributes of leadership in the Russian mass consciousness.

The construct "ambition" was surprisingly rarely mentioned in the experimental group consisting of oil company managers. At the same time, the construct "hot temper" was the most frequent (57\%), closely followed by "determination" (50\%). "Weight" marks of these two constructs were high (2.1 and 2.2, correspondingly). The construct "impulsiveness" in the third experimental group was not frequent (only $37 \%$ of the interviewees), but its weight was still rather high (2.0).

Lexico-semantic analysis of constructs and comparison of synonyms proved that constructs groups "determination-ambition-courage" and "activeness-impulsiveness-initiative" were consistently the most frequent and the most important in all the experimental groups. Opposing qualities (thoughtfulness, kindheartedness, etc.) were, firstly, much less frequent and, secondly, received much lower importance marks. In other words, the interviewees did not see much of these qualities in those whom they considered to be leaders.

The results of experiment allowed us to formulate a new hypothesis: the image of leadership in the Russian mass consciousness is rather stable and possesses certain key characteristics. The main qualities expected from a leader are impulsiveness, initiative and determination-i. e, qualities associated with extrovert temperaments. To prove this hypothesis, we organized the following experiment.

The pilot experiment involved 10 interviewees none of whom was connected with the previous experimental groups. They were given the list of eight leaders: Gaius Julius Caesar, Jeanne d'Arc, Elizabeth I, Nelson Mandela, Angela Merkel, Mahatma Gandhi, Mao Zedong, Katherine the Great. We used the following criteria when selecting leaders for the pilot experiment:

- Equal representation of male and female leaders;

- Leaders belonging to various cultures and historical eras;

- Supposed insignificant acquaintance of the interviewees with the real facts of biography and psychological traits of suggested leaders.

Our idea was that, if interviewees are unable to use real knowledge about suggested leaders, they will project their general opinion of leaders and leadership, thus giving us insights into their psychic reality.

For each of the leaders we suggested the interviewees the list of 12 qualities: sociable, impulsive, peaceful, active, reliable, quiet, initiative, reserved, anxious, aggressive, optimistic, and thoughtful. These qualities were specially selected - they are classic characteristics of temperament suggested by Hans Eysenck. From the full list of such characteristics we selected only 12, 3 for each temperament type. The interviewees were asked to select four qualities that would suit a given leader the most. In the printed forms the order of the qualities near each of the leader names was different. We believe that such organization of the text makes interviewees pay more attention to the stimulus material and thus make more rational selections, deeper and more accurately reflecting their psychic reality.

Table 2. Temperament qualities attributed to leaders

\begin{tabular}{lllll}
\hline Temperament type & M & F & Total & Median coefficient \\
\hline Sanguine type & & & & \\
sociable & 16 & 10 & 26 & 0.968944099 \\
optimistic & 9 & 2 & 11 & 0.409937888 \\
$\quad$ initiative & 27 & 18 & 45 & 1.677018634 \\
$\begin{array}{c}\text { Choleric type } \\
\text { active }\end{array}$ & 27 & 23 & 50 & 1.863354037 \\
\hline
\end{tabular}




\begin{tabular}{cllll}
\hline aggressive & 14 & 13 & 27 & 1.00621118 \\
impulsive & 15 & 13 & 28 & 1.043478261 \\
Phlegmatic type & & & & \\
thoughtful & 16 & 23 & 39 & 1.453416149 \\
peaceful & 12 & 5 & 17 & 0.633540373 \\
reliable & 12 & 11 & 23 & 0.857142857 \\
Melancholic type & & & & \\
reserved & 9 & 15 & 24 & 0.894409938 \\
anxious & 7 & 14 & 21 & 0.782608696 \\
quiet & 6 & 5 & 11 & 0.409937888 \\
\hline
\end{tabular}

When analyzing the results of the pilot experiment we also separated temperament traits attributed to make and female leaders. The research shows that female leaders are perceived as more thoughtful, reserved and anxious, while male leaders are more sociable, optimistic and peaceful. Nevertheless, the general perception of leadership remains the same, regardless of the gender of leaders.

Traits most frequently attributed to leaders are: active, initiative, thoughtful, impulsive, and aggressive. The median coefficient of these traits is above one which means that their frequency was higher than the average frequency of a trait in the experimental group. It must be noted that three of the five most frequent traits correspond to the choleric type of temperament, one to sanguine type, one to phlegmatic type. The traits corresponding to the melancholic type of temperament are seldom associated with leaders.

\section{Conclusions}

The two experiments described above allowed us to formulate the following conclusions:

Leaders and leadership are perceived through the prism of certain stereotypes and expectations. These expectations are determined culturally and historically, that is why leadership expectations may vary from one community to another. Disparity between the image of a real leader and the concept of leader existing in the psychic reality of a given community can cause the leader great difficulties in gaining the support of potential followers, in making them share his system of values and his existential vector.

1) Typical qualities expected from a leader in the Russian society are determination, impulsiveness, and activity. Such qualities as ethics or morals do not play an important role in the image of leader in the Russian mass consciousness.

2) Regardless of gender, age or culture, leaders are expected to have the traits of the choleric type of temperament. The traits of sanguine or phlegmatic are less associated with leadership, while a person demonstrating the traits of the melancholic type of temperament will probably never be considered a leader.

We suggest the two main principles of addressing the phenomenon of leadership: 1) leadership is an integral trait of personality and represents a person's willingness and ability to influence the environment with his values and ideas. Leadership starts with the person creating a system of values that can make people act that can serve as the meaning of their lives. Existential reflection is the necessary basis of leadership. 2) Leadership as a phenomenon of "psychic reality" and differs from one culture to another. To be effective, to successfully interact with potential followers, a leader must correspond to the image of leader existing in the mass conscious of a given culture. These two principles allow us to analyze leadership as truly integral phenomenon, combining intrapsychic existential basis with social interaction models resulting from the image of leader in the mass consciousness.

\section{Acknowledgements}

We would like to acknowledge the contribution made by all the experts, students and others involved in this study, particularly the team of Institute of Practical Psychology of NOU VPO "East-European Institute".

\section{References}

Adler, A. (1995). Practice and theory of individual psychology (p. 292). Moscow.

Anikina, V. G. (2000). Existential reflection of personality in problem-conflict situations. Moscow. 
Frankl, V. (1996). Man's search for meaning. Moscow.

Fransella, F., \& Bannister, D. (1987). New method of studying personality: A manual for repertory grid technique. Moscow.

Leontiev, D. A. (2011). New reference points for understanding personality in psychology: From the necessary towards the possible. Voprosy Psykhologii, 1, 3-28.

Morov, A. V. (2014). Leadership and existential reflection in the system of personality's social-psychological adaptation. Kazan pedagogical journal, 106(5), 118-124.

Sergienko, E. A. (2013). The problem of relationship between subject and personality. Psychologic Journal, $34(2), 5-16$.

\section{Copyrights}

Copyright for this article is retained by the author(s), with first publication rights granted to the journal.

This is an open-access article distributed under the terms and conditions of the Creative Commons Attribution license (http://creativecommons.org/licenses/by/3.0/). 